\title{
Factor space for the development of sustainable energy technologies in construction
}

\author{
Lyudmila Myshovskaya ${ }^{1}$, Olga Mescheryakova ${ }^{1}$,Vyacheslav Vlasenko ${ }^{1, *}$ and Anatoly \\ Bukreev $^{1}$ \\ ${ }^{1}$ Voronezh State Technical University, Moscow Avenue, 14, Voronezh, 394026, Russia
}

\begin{abstract}
Sustainable development of construction and housing and utilities sector is impossible without ensuring energy efficiency and environmental friendliness of the production and operation of facilities. The authors consider it possible to ensure this through the implementation of a scientifically based innovation strategy of entities at all levels of the economy. The authors postulate the expediency of forming a strategy for the development of sustainable energy technologies based on foresight technology, taking into account the network nature of the interaction of participants and the need to coordinate micro and meso level strategies based on the creation of "innovation growth points". To select the directions of strategic development of sustainable energy technologies and assess the effectiveness of their implementation, a list of analytical indicators of factors and results of the development is needed. Based on the adoption of the foresight methodology as a basis for building a strategy, and also based on the systems approach and the theory of self-organization of non-equilibrium systems, the need to develop a topology of indicators of the analytical unit as a basis for assessing the current state and heredity of the micro and meso level system has been proved. The authors proposed methodological provisions on the composition and structure of analytical indicators. On the basis of a statistical analysis of a number of indicators, the expediency of creating "innovation growth points" in the region in order to increase the efficiency of diffusion of innovative energy technologies in both intersectoral and interregional projections has been empirically proven.
\end{abstract}

\section{Introduction}

One of the most important problems of the current stage of economic reform in the Russian Federation is the need for a radical change in the management of the investment development of industries. In cities, first of all, this concerns construction as a systemforming activity, as well as the housing and utilities service sector as a system that ensures the life activity of the population. In general, the above mentioned spheres form the basis of a sustainable, and consequently, energy-efficient and environmentally friendly development of the country's economy [1].

\footnotetext{
* Corresponding author: slava.vlasenko.80@mail.ru
} 
Sustainable competitiveness of economic entities of construction and housing and utilities sector in the modern conditions of the knowledge economy can be ensured only with the advancing development of innovations and the intensification of innovative activities [2]. It is the innovative activity and effectiveness of economic entities that is the imperative of sustainable development of both them [3] and the cluster entities formed by them, spheres of activity and complexes formed according to heterarchical and hierarchical principles, as well as territories and regions of activity.

Organizational and economic approaches to the formation of the mechanism for the innovative development of construction enterprises and the housing and utilities services sector can be grouped and presented within the following main management processes: organization of information support; distribution of functions between structural divisions and official bodies on the basis of responsibility centers; establishment of new functional responsibilities of structural units for the development and implementation of innovative development strategies; determination of the rights and responsibilities of managers and structural units for the introduction of new and improving technologies.

The sequence of formation of the mechanism of innovative development of construction enterprises and the housing and utilities services sector is implemented within several main stages [4]:

1. Analysis of the state of innovation processes in the previous period, development of recommendations;

2. Development of competitive innovative behavior in the upcoming period, setting goals and objectives and coordinating them with corporate development plans;

3. The study of innovative activity in the previous period and the assessment of the current state of the innovation infrastructure;

4. Formation of innovation strategies, coordination of their terms, resources and performers;

5. Determination of economic efficiency, selection and formation of a portfolio of innovative projects;

6. Assessment of innovative potential and provision of effective operational management at the corporate level of innovative development strategies;

7. Analysis and control of the set and achieved strategic goals of innovation development, identification of deviations.

This mechanism reveals the trajectory of innovative development, the so-called loops of mutual amplification, which create a synergy effect: new technologies $\rightarrow(1)$; new equipment $\rightarrow(2)$; increase of requirements for the qualification of workers $\rightarrow(3)$; increase in labor productivity $\rightarrow(4)$; increase in the quality of services rendered $\rightarrow(5)$; increase in sales $\rightarrow(6)$; profit growth $\rightarrow(7)$; investment growth $\rightarrow(8)$.

At the same time, the trajectory of innovative development is determined by the action of the innovation multiplier, which shows how much the total volume of innovation products increases with the increase of investment in the innovation sector of the economy. The most important in the composition of innovative mechanisms is the mechanism of strengthening, which is implemented in the presence of restrictions caused by a combination of internal and external factors that impede the innovative activity of economic entities. In this projection, the justification of the factor space is the most important task that must be solved in order to develop and implement effective management actions, including at the strategic level.

In addition, the identification and analysis of factor space must be carried out within a single general concept [5]. 


\section{Materials and Methods}

According to the proposed conceptual scheme for studying the problem of forming innovation strategies (Fig. 1), a separate analytical unit should be highlighted.

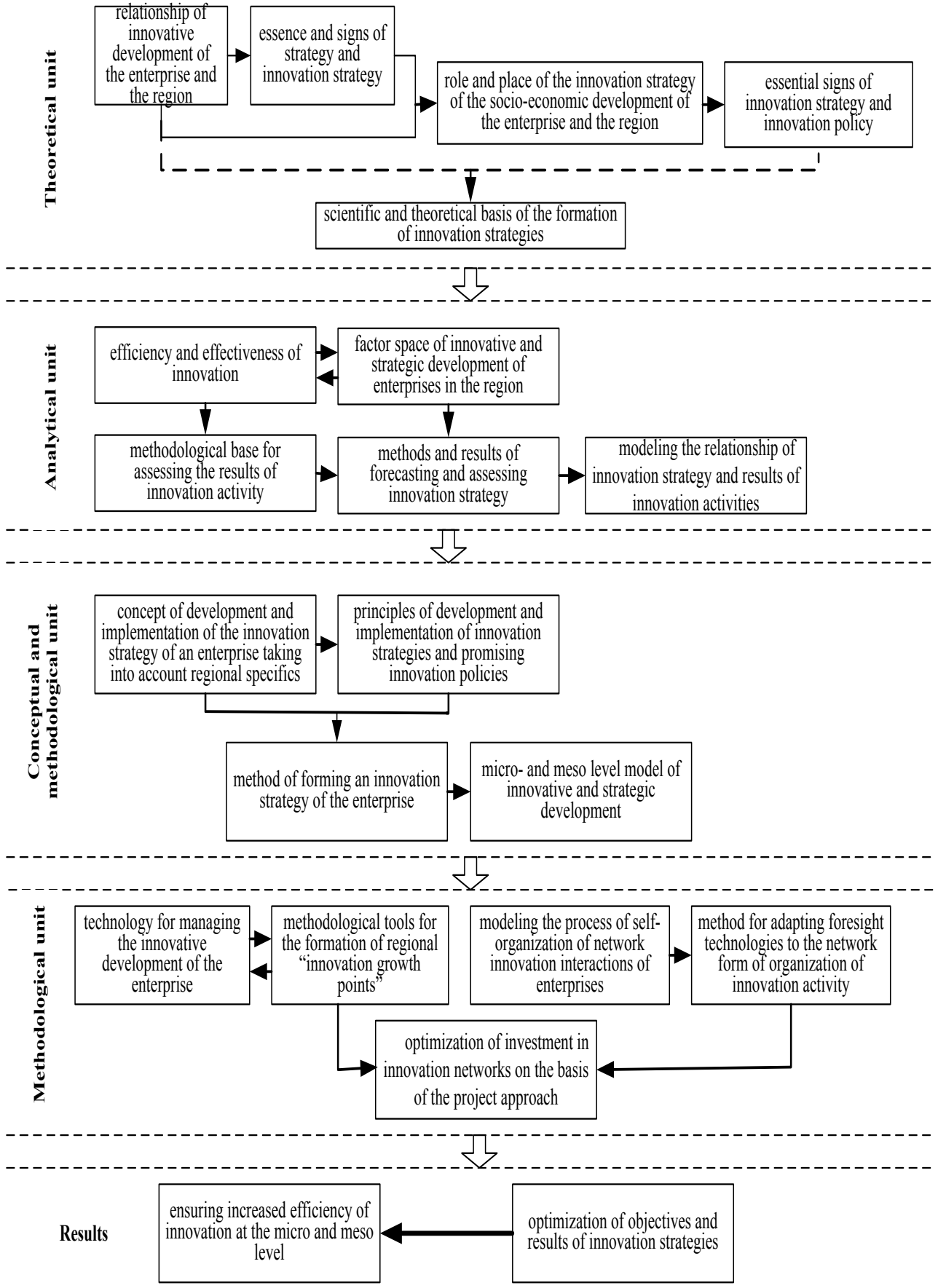

Fig. 1. Conceptual scheme for studying the problem of formation of innovation strategies. 
Taking the methodology of the foresight [6,7] as a key methodological element of the strategy, the analytical unit is basic in characterizing the current state, heredity, and the results of self-organization of economic systems of the micro and meso level. Accordingly, within the analytical unit, it was proposed to distinguish two groups of indicators: factorial and resulting.

\section{Results}

Based on the classification of economic systems according to the level of management at the macro, meso, and micro levels, it is necessary to provide a structure of analytical components for each level of the management system. However, taking into account the thesis about the fractality of the management system [2], we consider it expedient to present the problems of innovative and strategic development in the projection of the analytical unot of the concept in the following form (Fig. 2).

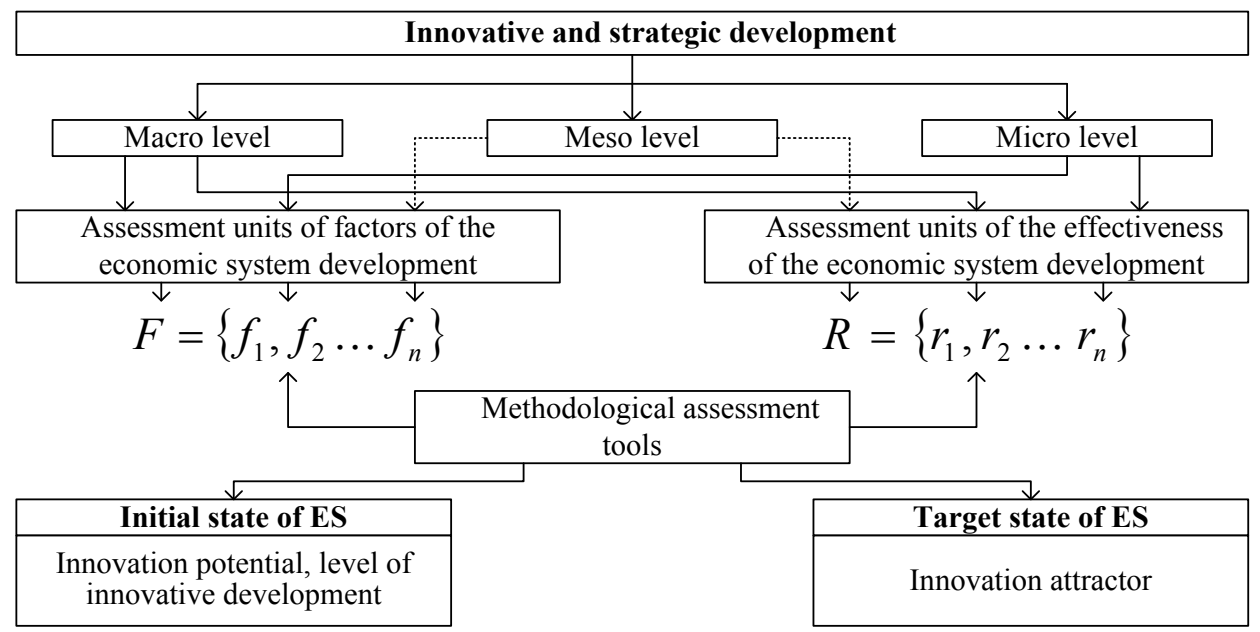

Fig. 2. Issues of innovative and strategic development in the projection of the analytical unit.

Accordingly, the foresight technology is clearly visible in this projection $[7,8]$ (the state of the economic system is the target attractor). Indicators of development factors characterize the current state of the system, the achieved level of innovative development, the capabilities of the country, region and enterprise for further innovative development, the existing innovation potential. The performance indicators characterize the target state of the system, a promising attractor of innovative development, formed within the foresight. In the traditional strategic planning, these indicators characterize the effectiveness of the planned innovation policy. Based on the concept of innovation policy adopted by us [9], performance indicators should reflect the specifics of the innovation process in its network form.

The most important task of the study is to select and form a set of assessment criteria and their units, both with respect to the factor space of the innovative and strategic development of the economic system, and with respect to the target indicators.

On the basis of the fractal structure of the management system in the economy presented in Figure 1, we consider it expedient to correlate the fundamental basis for the formation of innovation strategies with the necessary indexes and indicators (Fig. 3). 


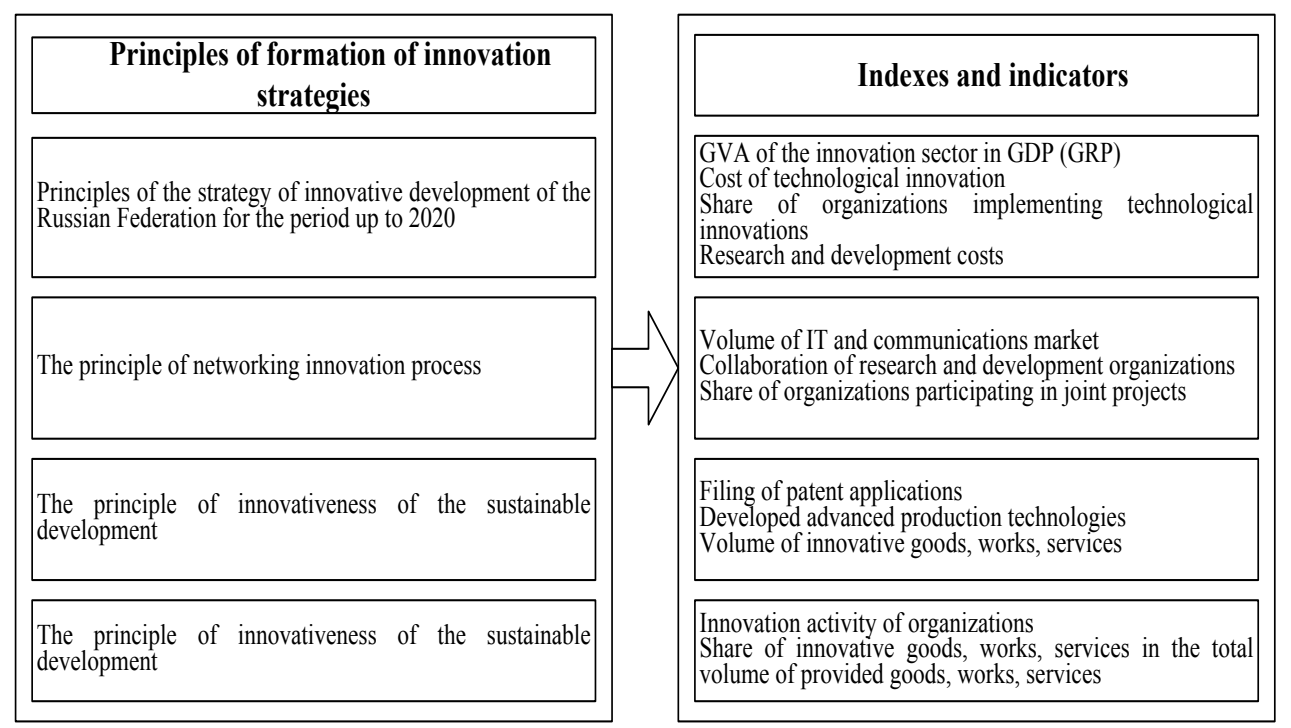

Fig. 3. Interrelation of innovative development indicators and principles of innovation strategies formation.

Thus, the need to take into account at the macro level the target indicators of the Strategy for the Innovative Development of the Russian Federation for the period up to 2020 leads to the inclusion of criteria, which characterize the achievement of the goals of the Strategy and the solution of the tasks set, in the "factors-results" assessment units.

Similarly, following the principle of fractality, the criteria for the level of innovative development are taken into account in accordance with the Strategy for Social and Economic Development of the Region. Also, according to the principle of fractality, the need to take into account target criteria and factor indicators in the projection of the innovative development of the industry (type of activity, complex, cluster) is proved.

Based on the modern network form of the innovation process [10], the principle of networking the innovation process is highlighted, which postulates not only the plurality of stakeholders of the innovation process and its formative projects but also the implementation of the modern innovation process in the network form, which contributes to the emergence of a synergistic effect of interaction between the entities of innovation activity and increase its efficiency. In accordance with the principle of networking, it is necessary to take into account the criteria characterizing the level of communication interactions between the entities of the innovation network.

The principle of innovative sustainable development, postulating technological and technical innovations as a source and/or catalyst for changes in the parameters of the economic system [2], forms the growth of inventive activity and accelerates the process of innovation commercialization as a dominant of innovative development, which makes it necessary to take into account relevant indicators.

The low level of commercialization of innovations demonstrates the need to take into account the principle of the diffusion of innovations in strategic planning of innovation activity, postulating the feasibility of creating "innovation growth points" in the region. Accordingly, there is a need to account for the innovation activity of enterprises and organizations, as well as the effectiveness of this activity.

The practical application of the proposed model of the analytical unit in the construction of innovation strategies can be complicated by the possibility of a dialectical transition of the factor characteristics to the resultant ones. 
We have analyzed a number of indicators of innovative development in the projection of sectoral and regional specifics, and also relative to the size of enterprises.

First, an analysis of the innovation activity of enterprises was carried out. The results of the statistical analysis of a sample of data on innovation activity of enterprises by region for the first half of 2018 are shown in Table 1.

Table 1. The results of statistical analysis of a sample of data on innovation activity of enterprises by regions in the first half of 2018.

\begin{tabular}{|l|c|}
\hline \multicolumn{1}{|c|}{ Statistical analysis index } & Result \\
\hline Average share of organizations implementing innovations, \% & 7.77 \\
\hline Standard deviation & 4.46 \\
\hline Sample variance & 19.9 \\
\hline Kurtosis & 3.07 \\
\hline Asymmetry & 1.52 \\
\hline Minimum share of organizations implementing innovations, \% & 0.2 \\
\hline Maximum share of organizations implementing innovations, \% & 24.7 \\
\hline
\end{tabular}

As can be seen from Table 1, on average, innovations were implemented by less than $8 \%$ of organizations, while the maximum share was almost $25 \%$ (in the Chuvash Republic). The obtained values of the coefficients of asymmetry and kurtosis are significant, which is confirmed by calculating the ratio of the asymmetry coefficient $s$ to the error value $\mathcal{T}_{a s}$ (i.e. the condition: $s /{ }^{D_{a s}}<3$ is not fulfilled), which indicates that it is impossible to apply a normal random distribution function to this indicator.

A similar trend in the distribution of regions by the share of innovatively active enterprises can be traced throughout the entire analyzed period (since 2010). Thus, the innovation activity of enterprises in the regional projection is uneven, which can formulate an assumption about the cluster nature of the placement of innovatively active enterprises and organizations and the presence of regional drivers of innovative development.

Similar calculations in the sectoral projection have a similar trend (Table 2).

Table 2. The results of statistical analysis of a sample of data on innovation activity of enterprises by types of economic activity in the first half of 2018.

\begin{tabular}{|l|c|}
\hline \multicolumn{1}{|c|}{ Statistical analysis index } & Result \\
\hline Average share of organizations implementing innovations, \% & 11.41 \\
\hline Standard deviation & 10.14 \\
\hline Sample variance & 102.81 \\
\hline Kurtosis & 2.16 \\
\hline Asymmetry & 1.43 \\
\hline Minimum share of organizations implementing innovations, \% & 0.8 \\
\hline Maximum share of organizations implementing innovations, \% & 47.1 \\
\hline
\end{tabular}

From the results of the analysis it follows that the sectoral differentiation of innovation activity of enterprises far exceeds the territorial, and this trend is also observed throughout the entire period of the analysis (Fig. 4). 


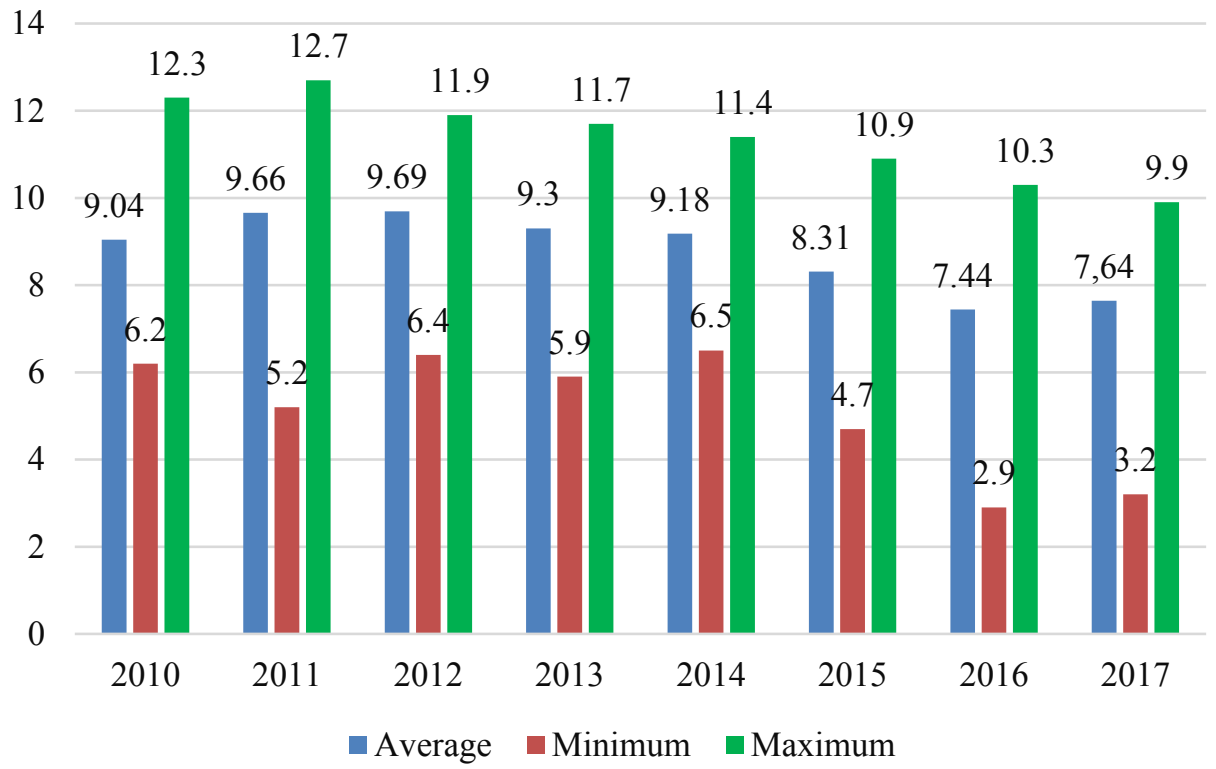

Fig. 4. Dynamics of average, maximum and minimum shares of organizations that implemented innovations in the sectoral projection.

Consequently, there is both a sectoral and territorial differentiation in the level of innovation activity of organizations, which empirically confirms the hypothesis of the unevenness of innovative development and the feasibility of the formation of "innovation growth points".

Let's conduct a similar analysis in terms of the volume of innovative products.

The results of the statistical analysis of a sample of data on the volume of output of innovative products by region for the first half of 2018 are shown in Table 3.

Table 3. The results of the statistical analysis of a sample of data on the volume of output of innovative products by region for the first half of 2018.

\begin{tabular}{|l|c|}
\hline \multicolumn{1}{|c|}{ Statistical analysis index } & Result \\
\hline Average volume of innovative products, mln.rub. & 53387 \\
\hline Standard deviation & 89330.00 \\
\hline Sample variance & 7979849691 \\
\hline Kurtosis & 6.18 \\
\hline Asymmetry & 2.45 \\
\hline Minimum volume of innovative products, mln.rub. & 22.75 \\
\hline Maximum volume of innovative products, mln.rub. & 435557.66 \\
\hline
\end{tabular}

As can be seen from the data in table 3, there is a large variation in the volume of innovative products within the sample. This fact also indicates a high level of regional differentiation in the level of innovative development. At the same time, the assessment of the dynamics indicates a general positive dynamics of the volume of innovative products, both on average and extreme values.

A similar analysis in the sectoral projection also showed a rather high degree of differentiation in the volumes of innovative products (Table 4). 
Table 4. The results of statistical analysis of a sample of data on the volume of innovative products by types of economic activity in the first half of 2018 .

\begin{tabular}{|l|c|}
\hline \multicolumn{1}{|c|}{ Statistical analysis index } & Result \\
\hline Average volume of innovative products, mln.rub. & 93264.11 \\
\hline Standard deviation & 157601.5 \\
\hline Sample variance & $2.48 \mathrm{E}+10$ \\
\hline Kurtosis & 2.70 \\
\hline Asymmetry & 1.92 \\
\hline Minimum volume of innovative products, mln.rub. & 2.89 \\
\hline Maximum volume of innovative products, mln.rub. & 605654.8 \\
\hline
\end{tabular}

As can be seen from the table, sectoral differentiation is also great.

The empirical analysis of the innovation activity of enterprises with respect to size, along with the study of earlier studies in this field [11], also indicates a high level of differentiation.

All of these aspects should be taken into account in the formation of innovation strategies not only for enterprises but also for industries and regions.

\section{Discussions}

When forming the factor space, it is necessary to identify which factors of the external and internal environment have the greatest influence on the nature of the formation of the innovation strategy of construction and housing and utilities enterprises. At the same time, the current situations do not allow for a clear distinction between which factors are internal and which are external.

The existing relationships within the complex have led to the fact that the internal factors of some elements of the complex appear as external factors for other elements, the internal factors of which, in turn, are external for other elements, creating a closed chain of interrelations of factors.

At the same time, it is possible to single out a number of main factors affecting the nature of innovative and strategic development, among which, based on a reasonable level of regional differentiation, one should single out the factors of the meso level. Most of these factors affect not only the construction enterprises and the housing and utilities services sector but also the development of the entire country's economy. Thus, it is advisable to identify a number of factors affecting specifically the construction and housing and utilities services sector. These factors cause a sectoral differentiation of the level of innovative development of economic entities.

As the analysis showed, there is a sufficient degree of correlation between the innovation strategy of the enterprise and the development strategies of the macro and meso level. In addition, taking into account the specifics of the network innovation process, the communication nature of the network, the most important aspect of the formation of an innovation strategy for an enterprise is to optimize interaction with the strategy of the region.

At present, when competition between regions for the attracted volume of investment is high [12], it is necessary to develop effective measures that increase investment and innovation attractiveness, which will increase the level of innovation activity of enterprises of strategic industries on the basis of the innovation multiplier action. 


\section{Conclusion}

We have proven that an effective state zoning policy contributes to enhancing the diffusion of innovations both in the horizontal (within the region) and in the vertical (between sectors) projections by creating "innovation growth points" in accordance with the "neighborhood effect" by T. Hagerstrand.

Accordingly, it is advisable to assess not so much the current state as the specificity and heredity of the studied economic system; identifying the set of attractors of this system, including the target ones; forecasting the possible trajectories of the system development towards the selected attractors; development of initiated actions, "catalysts" of system fluctuations. This set of parameters can be implemented using the foresight methodology, highlighting a separate analytical unit with a scientifically based set of indicators.

\section{References}

1. Kh. Gumba, S. Belyaeva, IOP Conference Series: Earth and Environmental Science, 012163 (2017)

2. S. Uvarova, D. Voronov, S. Erypalov, MATEC Web of Conferences "International Science Conference SPbWOSCE-2016 "SMART City", 08036 (2017)

3. Kh. Gumba, E.A. Prokhin, Ekonomika i predprinimatelstvo 4-1(69), 841-844 (2016)

4. A.N. Kirillova, N.I. Trukhina, FES: Finansy. Ekonomika. Strategia 7, 31-35 (2015)

5. P.G. Grabovy, E.U. Okolelova, N.I. Trukhina, Izvestia visshikh uchebnykh zavedenii. Tekhnologia tekstilnoi promishlennosty 1(367), 78-82 (2017)

6. E.A. Makarova, A. Sokolova, Foresight 16(1), 75-91 (2014)

7. A.V. Sokolov, Harvard Business Review Russia 5, 95-99 (2017)

8. S. Zanoni, B. Marchi, M. Pasetti, L. Zavanella, A Supply Chain Model with Integrated Thermal Recovery and Electricity Generation from Industrial Waste Heat (Industrial, 2018)

9. S. Uvarova, V. Vlasenko, A. Bukreev, L. Myshovskaya, O. Kuzina, E3S Web of Conferences 33, 03022 (2018)

10. I.G. Lukmanova, M.Y. Mishlanova, International Journal of Economics and Financial Issues 5, 208-216 (2015)

11. O.V. Papelniuk, E.I. Sizova, Vestnik Belgorodskogo gosudarstvennogo tekhnologicheskogo universiteta im. V.G. Shukhova 1, 124-127 (2015)

12. E.V. Nezhnikova, S.R. Sultanov, Ekonomika i predprinimatelstvo 5-1 (82-1), 193-197 (2017)

13. A. Borboni, F. Aggogeri, N. Pellegrini, R. Faglia, Advanced Materials Research, 590, $\begin{array}{lll}\text { pp. } & \text { (2012) DOI: } & \text { 10.4028/www.scientific.net/AMR.590.399 }\end{array}$ 